\title{
IncRNA MALAT1, HOTTIP and PVT1 as predictors for predicting the efficacy of GEM based chemotherapy in first-line treatment of pancreatic cancer patients
}

\author{
Cui-Juan Wang ${ }^{1,3, *}$, Sheng-Bin Shi ${ }^{2, *}$, Jing Tian ${ }^{2}$, Jun $\mathrm{Xu}^{2}$ and Zuo-Xing Niu ${ }^{2}$ \\ ${ }^{1}$ Shandong University of Traditional Chinese Medicine, Jinan, P.R. China \\ ${ }^{2}$ Department of Medical Oncology, Shandong Cancer Hospital Affiliated to Shandong University, Jinan, P.R. China \\ ${ }^{3}$ Central Laboratory, Shandong Academy of Occupational Health Medicine, Jinan, P.R. China \\ *These authors have contributed equally to this work \\ Correspondence to: Zuo-Xing Niv, email: nzx6677@163.com \\ Keywords: advanced pancreatic cancer; GEM based chemotherapy; first-line therapy; IncRNA MALAT1; HOTTIP and PVTI \\ Received: January 11,2017 Accepted: June 20,2017 Published: July 18, 2017 \\ Copyright: Wang et al. This is an open-access article distributed under the terms of the Creative Commons Attribution License 3.0 \\ (CC BY 3.0), which permits unrestricted use, distribution, and reproduction in any medium, provided the original author and source \\ are credited.
}

\section{ABSTRACT}

This study evaluated the Inc-RNAs as biomarker to predict efficacy of gemcitabine (GEM) based chemotherapy as the first-line treatment for locally advanced or advanced pancreatic cancer patients. We selected 62 patients with GEM based chemotherapy and divided two groups according to the PFS. We found that the expression of MALAT1, HOTTIP, and PVT1 in serum had a significant difference among the two groups. Furthermore, we estimated the PFS and response rate based on the expression levels of MALAT1, HOTTIP and PVT1. The response rate of two groups showed a significant difference according to the expression levels of MALAT1, HOTTIP and PVT1. Based on the expression levels of MALAT1, HOTTIP and PVT1, the response rate of high expression of PVT1 and low expression of PVT1 was respectively $14.8 \%$ and $37.1 \%$ and $18.2 \%$ (high HOTTIP group) and $37.9 \%$ (low HOTTIP group), $10.7 \%$ (high MALAT1 group) and $41.1 \%$ (low MALAT1 group). The PFS of patients with high and low expression levels PVT1 was 2.6 months and 4.0 months $(p<0.001)$, respectively. The PFS of patients with high and low expression levels of HOTTIP was 2.7 months and 4.1 months $(p<0.001)$, respectively, and the PFS of patients with high and low expression levels of MALAT1 was 3.0 months and 3.7 months $(P=0.026)$, respectively. The results suggest that MALAT1, HOTTIP and PVT1 as predictors to predict the efficacy of GEM based chemotherapy in first-line treatment of pancreatic cancer patients.

\section{INTRODUCTION}

Pancreatic cancer is one of the most aggressive cancers with a high mortality rate in the world [1]. Despite the efforts of surgery, chemotherapy and radiation, the five-year survival rate is still less $5 \%$ and median survival time is about 4-6 months [2], Because of early metastasis and resistant to chemotherapy and radiation therapy [3]. Due to lack of specific early symptoms, most patients appear an advanced stage of disease at the time of diagnosis. For patients with advanced stage, chemotherapy plays an important role. Although the development of chemotherapy, gemcitabine-based therapy remains the standard first line treatment [4]. To date, carbohydrate antigen 19-9 (CA19-9) has certain role to predict the efficacy, but the specificity and sensitivity are very low [5]. Therefore, it is urgent to search for a sensitive biomarker to predict the efficacy of gemcitabine-based therapy. 
Table 1: Patients' characteristics

\begin{tabular}{|c|c|c|c|}
\hline Factor & PFS $\leq 3$ months groups & PFS $>3$ months groups & $\mathbf{P}$ \\
\hline Median age (range) & $56.5(37-68)$ & $59.0(36-69)$ & \\
\hline Gender & & & 0.62 \\
\hline Male & 18 & 14 & \\
\hline Female & 15 & 15 & \\
\hline Performance status & & & 0.40 \\
\hline $0-1$ & 17 & 18 & \\
\hline 2 & 16 & 11 & \\
\hline First line regimen & & & 0.38 \\
\hline Gemcitabine/Cisplatin & 11 & 13 & \\
\hline Gemcitabine/Nab-paclitaxel & 6 & 8 & \\
\hline Gemcitabine/Oxaliplatin & 15 & 9 & 0.66 \\
\hline \multicolumn{4}{|l|}{ Clinical stage } \\
\hline III & 12 & 9 & \\
\hline IV & 21 & 20 & \\
\hline Tumor location & & & 0.60 \\
\hline Head & 23 & 20 & \\
\hline Body & 7 & 8 & \\
\hline Tail & 3 & 1 & \\
\hline Differentiation & & & 0.47 \\
\hline Well & 19 & 15 & \\
\hline Moderate & 8 & 5 & \\
\hline Poor & 6 & 9 & \\
\hline
\end{tabular}

Long non-coding RNAs (lncRNA) are a class of noncoding RNA with more than 200 nucleotides, but lack protein coding capacity [6, 7]. More and more investigations have demonstrated that lncRNAs exert an important role in proliferation, poptosis and migration. The expression levels of certain lncRNAs are associated with cancer recurrence, cancer progression, metastasis, and poor prognosis [8-10]. Some studies have reported that some lncRNAs such as H19, HOTAIR, HOTTIP, MALAT1,PVT1,ENST0000048073 9,Gas5,AF339813,LOC389641,AFAP1-AS1, BC008363, GAS,HMlincRNA717,HOTAIRM1,HULU [11-19] are most closely associated with PC. Therefore, lncRNAs might help to provide novel potential molecular markers for predicting the efficacy of gemcitabine-based.

Some studies shown that lncRNAs can be readily detected by qPCR from the body fluids, i.e. serum, plasma, gastric liquids, or urine [20]. In our study, we evaluated the levels of some lnc-RNAs in peripheral blood of patients with pancreatic cancer and analysed the correlation between lnc-RNAs, Progression-Free-Survival (PFS) and Response rate.

\section{RESULTS}

\section{Patient characteristics}

In our study, all patients were histologically diagnosed with pancreatic adenocarcinoma and were classified as locally advanced or advanced pancreatic cancer by CT. Total 62 patients received the GEM based chemotherapy as first-line treatment. According to the PFS, we divided into less than three months groups of PFS (29 patients) and greater than three months groups of PFS (33 patients). The two group patients have no significant difference in sex, age, phase and chemotherapy regimens. The characteristics of the two group patients are summarized in Table 1. 
Table 2: The expression levels of Inc-RNAs according to the PFS

\begin{tabular}{|c|c|c|c|c|c|}
\hline & \multicolumn{2}{|c|}{ Overexpression level } & \multicolumn{2}{|c|}{ Downregulation level } & \multirow[t]{2}{*}{$\mathbf{P}$} \\
\hline & PFS $<3$ months & PFS $>3$ months & PFS $<3$ months & PFS $>$ 3months & \\
\hline H19 & 12 & 16 & 15 & 19 & 0.92 \\
\hline AFAP1-AS1 & 13 & 18 & 9 & 22 & 0.28 \\
\hline PVT1 & 19 & 8 & 10 & 25 & $<0.01$ \\
\hline HOTAIR & 16 & 19 & 14 & 13 & 0.63 \\
\hline HOTTIP & 23 & 10 & 11 & 18 & $<0.01$ \\
\hline MALAT1 & 20 & 8 & 13 & 21 & $<0.01$ \\
\hline ENST00000480739 & 9 & 20 & 11 & 22 & 0.84 \\
\hline Gas5 & 18 & 16 & 15 & 13 & 0.96 \\
\hline AF339813 & 14 & 19 & 11 & 18 & 0.72 \\
\hline LOC389641 & 8 & 20 & 10 & 24 & 0.94 \\
\hline ВC008363 & 10 & 22 & 13 & 17 & 0.32 \\
\hline HMlincRNA717 & 20 & 8 & 24 & 10 & 0.94 \\
\hline HOTAIRM1 & 15 & 19 & 12 & 16 & 0.92 \\
\hline HULU & 13 & 18 & 15 & 16 & 0.61 \\
\hline
\end{tabular}

Table 3: The difference of response according to the level of PVT1

\begin{tabular}{lccc}
\hline Response & High $\boldsymbol{P V T 1}(\mathbf{2 7})$ & Low PVT1 (35) & P \\
\hline CR & 0 & 0 & \\
PR & $4(14.8 \%)$ & $13(37.1 \%)$ & \\
SD & $10(37.0 \%)$ & $15(42.9 \%)$ & $<0.001$ \\
Response rate & $4(14.8 \%)$ & $13(37.1 \%)$ & $<0.001$ \\
Median PFS (95\% CI) & $2.6(2.2-2.9)$ months & $4.0(3.5-4.5)$ months & \\
\hline
\end{tabular}

\section{Response}

In the two groups, the expression levels of three lnc-RNAs (MALAT1, HOTTIP, PVT1) had a significant difference (Table 2). Furthermore, we divided patients into high and low expression levels of lncRNAs groups based the MALAT1, HOTTIP, PVT1. The response rate of two groups showed a significant difference according to the expression levels of MALAT1, HOTTIP, PVT1. The Response rate of high expression of PVT1 and low expression of PVT1 was respectively $14.8 \%$ and $37.1 \%$ and had a significant difference (Table 3). Based on the expression level of HOTTIP, MALAT1, the Response rate was respectively $18.2 \%$ (high HOTTIP group) and $37.9 \%$ (low HOTTIP group) and 10.7\%(high MALAT1 group) and $41.1 \%$ (low MALAT1 group) (Tables 4 and 5).

According to the expression levels of PVT1, MALAT1, HOTTIP, the PFS showed a significant difference. The PFS of patients with high and low expression levels PVT1 was 2.6 months (95\% CI, $2.2-2.9)$ and 4.0 months $(95 \% \mathrm{CI}, 3.5-4.5)(\mathrm{p}<0.001)$, respectively (Figure 1). The PFS of patients with high and low expression levels of HOTTIP was 2.7 months $(95 \%$ CI, 2.3-3.1) and 4.1 months (95\% CI, 3.6-4.7) $(\mathrm{p}<0.001)$, respectively, and the PFS of patients with high and low expression levels of MALAT1 was 3.0 months $(95 \%$ CI, 2.6-3.3) and 3.7 months $(95 \% \mathrm{CI}, 3.2-4.3)(\mathrm{P}=0.026)$, respectively (Figures 2 and 3).

\section{DISCUSSION}

At present, pancreatic cancer remains a highly malignant tumor and the prognosis is extremely poor. For many years, new drugs for cancer treatment have been appeared consecutively, but Gemcitabine-based treatment remained the first-line chemotherapy regimen for patients with advanced pancreatic cancer [21]. Although, the level of serum CA19-9 may help to predict the prognosis partly, the 
Table 4: The difference of response according to the level of HOTTIP

\begin{tabular}{lccc}
\hline Response & High HOTTIP (33) & Low HOTTIP(29) & P \\
\hline CR & 0 & 0 \\
PR & $6(18.2 \%)$ & $11(37.9 \%)$ & \\
SD & $7(21.2 \%)$ & $13(44.8 \%)$ & $<0.001$ \\
Response rate & $6(18.2 \%)$ & $11(37.9 \%)$ & $<0.001$ \\
Median PFS $(95 \% \mathrm{CI})$ & $2.7(2.3-3.1)$ months & $4.1(3.6-4.7)$ months & \\
\hline
\end{tabular}

Table 5: The difference of response according to the level of MALAT1

\begin{tabular}{lccc}
\hline Response & High $\boldsymbol{M A L A T 1 ~ ( 2 8 )}$ & Low $\boldsymbol{M A L A T 1}(\mathbf{3 4})$ & P \\
\hline CR & 0 & 0 \\
PR & $3(10.7 \%)$ & $14(41.1 \%)$ & $16(47.1 \%)$ \\
SD & $9(32.1 \%)$ & $14(41.1 \%)$ & 0.007 \\
Response rate & $3(10.7 \%)$ & $3.7(3.17-4.26)$ months & 0.026 \\
Median PFS (95\% CI) & $3.0(2.6-3.3)$ months & \\
\hline
\end{tabular}

situation is unsatisfying the need of individualized therapy $[22,23]$. Therefore, we have focused on searching reliable biomarkers to predict the therapeutic efficacy and avoid some ineffective patients to receive aggressive therapies.

LncRNAs were found to be more stable in that case situation of multiple freeze-thaw cycles, strong acid and base. Some studies have demonstrated that dysregulated expression of lncRNAs may independently predict patient outcome [24, 25]. Li et al. found that the expression of HOTTIP was up-regulated in pancreatic cancer tissues and demonstrated that HOTTIP was over-expressed in cancer tissues compared with non-tumoral tissues and elevated the ability of pancreatic cell proliferation and invasion. Targeted silencing of HOTTIP may enhance the antitumor effects of gemcitabine [12]. Furthermore, expression of HOTTIP has been identified as a negative prognostic

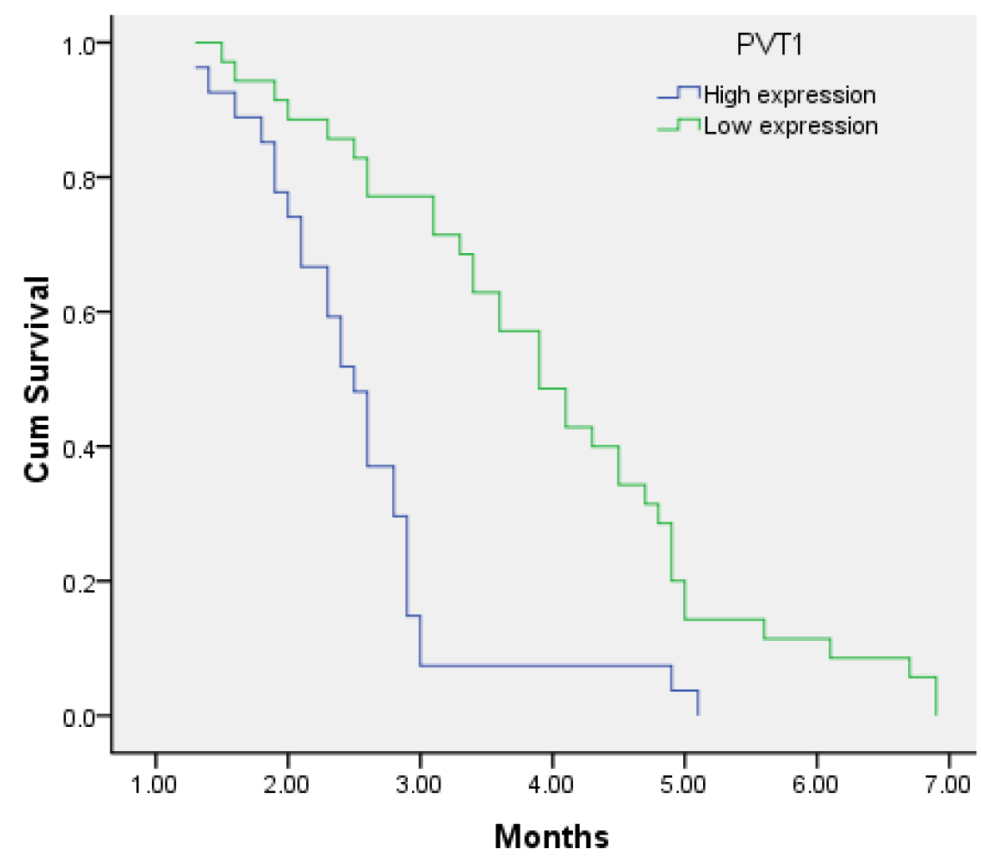

Figure 1: Kaplan-Meier analysis for PFS in pancreatic cancer patients with High expression level of PVT1 and low expression level of PVT1. $(\mathrm{P}<0.001)$. 
factor in hepatocellular carcinoma patients [26]. Another study shows that HOTTIP increases pancreatic cancer cell proliferation, survival, and migration through HoxA family genes other than HoxA13 [27].

One study has shown that PVT1 gene could regulate Gemcitabine sensitivity in human pancreatic cell line. The sensitivity of Gemcitabine was changed according to the situation of antisense orientation and sense orientation of full length PVT1 cDNA. Overexpression of PVT1 decreased gemcitabine sensitivity, while functional inactivation of the PVT1 enhanced Gemcitabine sensitivity [28]. Mechanism study demonstrated that the upregulated PVT1 could induce cell cycle genes and activation of the TGF $\beta 1$ signaling pathway and PVT1 binds to EZH2, recruits $\mathrm{EZH} 2$ to the miR-200b promoter, which increases histone H3K27 trimethylation level on the miR-200b

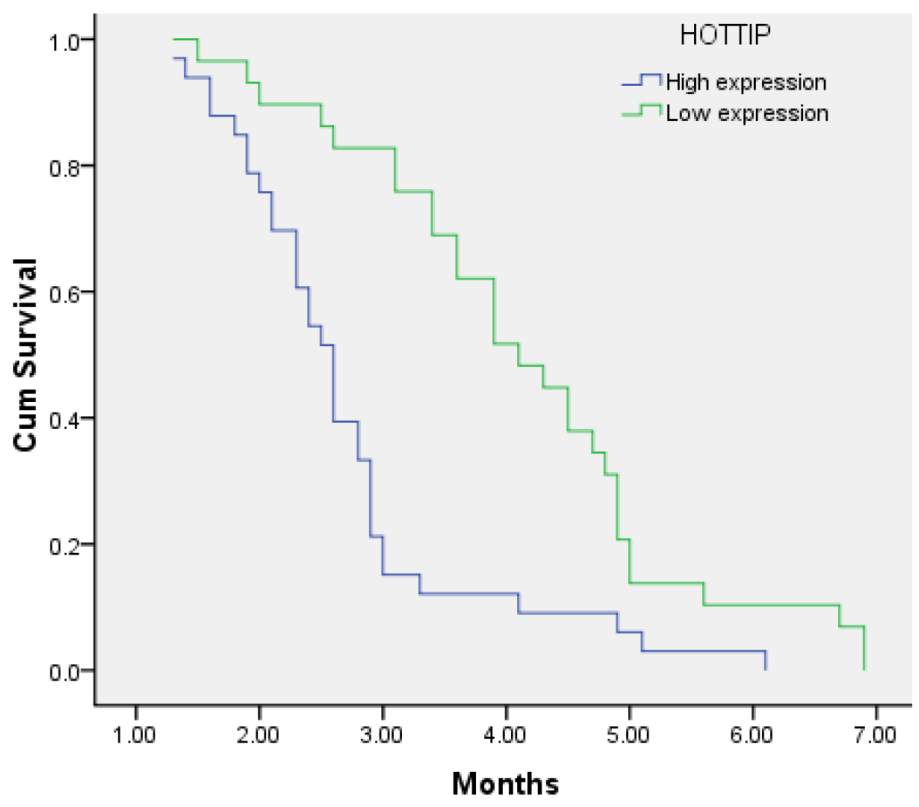

Figure 2: Kaplan-Meier analysis for PFS in pancreatic cancer patients with high expression level of HOTTIP and low expression level of HOTTIP. $(\mathrm{P}<0.001)$.

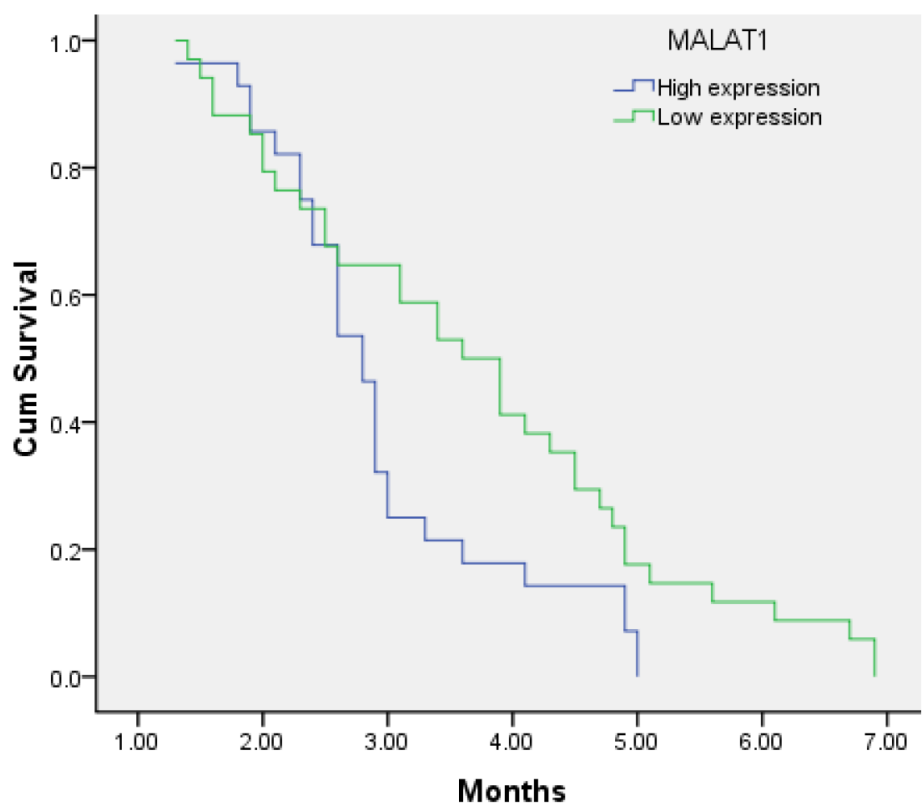

Figure 3: Kaplan-Meier analysis for PFS in pancreatic cancer patients with high expression level of MALTA1 and low expression level of MALTA1. $(\mathrm{P}<0.026)$. 
promoter, and inhibits miR-200b expression [29, 30]. Knockdown of MALAT1 expression inhibited PC cell proliferation, migration, and invasion in vitro by inducing G2/M cell cycle arrest, suppressing EMT and decreasing cancer stem-like properties $[13,31]$. In our study, the high and low expression level of lnc-RNAs had a different PFS and response rate. Above studies may also provide a certain confirmation.

In conclusion, our study suggested that PVT1, HOTTIP, MALAT1 was associated with the efficacy of first-line treatment with GEM based chemotherapy in pancreatic cancer. They may be novel non-invasive biomarkers for predicting the efficacy. The limitation of our study was that the sample size was small and a larger sample size is needed to confirm the results in the future. In-depth analysis of their biological functions is needed.

\section{MATERIALS AND METHODS}

\section{Patients}

The patients who take part in this study had histologically proven advanced pancreatic cancer. All patients received GEM based chemotherapy in first-line treatment between February 2014 and January 2016 at Shandong Tumor Hospital. The patient selection criteria were: age, 18-75 years old; ECOG performance status (PS) $\leq 2$; adequate hematological, hepatic function adrenal functions (white blood cell count $\geq 4.0 \times 10^{9} / 1$; neutrophil count $\geq 1.5 \times 10^{9} / 1$; platelet count $\geq 100 \times 10^{9} / 1$ and hemoglobin $\geq 10 \mathrm{~g} / \mathrm{dl} ;$ ALT and AST $\leq 2.5 \times$ upper limits of normal; total bilirubin $\leq 1.5 \times$ upper limits of normal; creatinine clearance $\geq 60 \mathrm{ml} / \mathrm{min}$ or creatinine $\leq$ upper limits of normal); and life expectancy greater than 3 months. All the patients had at least one measurable lesions by CT scan or MRI. Exclusion criteria were massive pleural effusion or ascites, active concomitant malignancy, brain metastasis, pregnant or lactating if patients were women. All the patients were informed, and the trial was authorized by the ethics committee of Shandong tumor hospital.

\section{Detection serum levels of IncRNAs}

Blood samples were collected before chemocherapy and then centrifuged at $3000 \times \mathrm{g}$ for $10 \mathrm{~min}$, and stored in RNase- and DNase-free tubes at $-80^{\circ} \mathrm{C}$ before use. Serum RNA isolation was performed using a Blood Total RNA Isolation Kit (RP4001, BioTeke, Beijing, China) according to manufacturer's protocol. RT and qPCR kits were used to evaluate the expression levels of the selected lncRNAs in the samples as described previously [32]. $\beta$-actin was used as control. The relative expression levels of each lncRNA was calculated using the $2^{-\Delta \Delta C t}$ method and was normalized to that of $\beta$-actin.

\section{Treatment and evaluation}

All patients received GEM based chemotherapy, including gemcitabine plus cisplatin, gemcitabine plus Nab-paclitaxel or gemcitabine plus Oxaliplatin. The dosages were described previously $[33,34]$. Treatment continued until a maximum of 6 cycles, progressive disease, unacceptable toxicity occurred, or withdrawal of patient consent. Before treatment, all patients were collected blood to test the level of serum lncRNAs and carbohydrate antigen (CA) 19-9(CA19-9). Tumor responses were evaluated every two cycles of treatment via computed tomography (CT) according to the Response Evaluation Criteria in Solid Tumors (RECIST, ver. 1.1).

\section{Statistical analysis}

All statistical analyses were performed using the SPSS 17.0 software package (SPSS Inc., Chicago, IL, USA). The correlations were analyzed using the Student's t-test, the Chi-square test and analysis of variance (ANOVA). Survival curves were analyzed according to the Kaplan-Meier method. All statistical tests were two tailed and results with $\mathrm{P}=0.05$ were defined as statistically significant.

\section{Abbreviations}

GEM, gemcitabine; CA19-9, carbohydrate antigen; lncRNA, long non-coding RNAs; PFS, progressionfree-survival; PS, performance status; CT, computed tomography; RECIST, response evaluation criteria in solid tumors.

\section{ACKNOWLEDGMENTS}

Not applicable.

\section{CONFLICTS OF INTEREST}

No author has any conflicts of interest to declare.

\section{FINANCIAL SUPPORT}

This work was supported by grants from Shandong Medicine and Health Science. Technology Project (2015WS0165) and key research and development plan of Shandong province (No. 2016GSF201142).

\section{REFERENCES}

1. Siegel RL, Miller KD, Jemal A. Cancer statistics, 2015. CA Cancer J Clin. 2015;65:5-29. 
2. Crawford SM. The importance of primary care for cancer diagnoses. Lancet Oncol. 2014;15:136-7.

3. Ryan DP, Hong TS, Bardeesy N. Pancreatic adenocarcinoma. N Engl J Med. 2014;371:1039-49.

4. Cartwright TH, Ginsburg A, Wilfong LS, Harrell RK, Hoverman JR. Use of first-line chemotherapy for advanced pancreatic cancer: FOLFIRINOX versus gemcitabine-based therapy. J Clin Oncol. 2014;32:Abstr 4132.

5. Wu E, Zhou S, Bhat K, Ma Q. CA 19-9 and pancreatic cancer. Clin Adv Hematol Oncol. 2013;11:53-5.

6. Ponting CP, Oliver PL, Reik W. Evolution and functions of long noncoding RNAs. Cell. 2009;136:629-41.

7. Seton-Rogers S. Non-coding RNAs: the cancer $\mathrm{X}$ factor. Nat Rev Cancer. 2013;13:224-5.

8. Mercer TR, Dinger ME, Mattick JS. Long noncoding RNAs: insights into functions. Nat Rev Genet. 2009; 10:155-9.

9. Kim K, Jutooru I, Chadalapaka G, Johnson G, Frank J, Burghardt R, Kim S, Safe S. HOTAIR is a negative prognostic factor and exhibits prooncogenic activity in pancreatic cancer. Oncogene. 2013;32:1616-25.

10. Nie Y, Liu X, Qu SH, Song EW, Zou H, Gong C. Long noncoding RNA HOTAIR is an independent prognostic marker for nasopharyngeal carcinoma progression and survival. Cancer Sci. 2013;104:458-64.

11. Kim K, Jutooru I, Chadalapaka G, Johnson G, Frank J, Burghardt R, Kim S, Safe S. HOTAIR is a negative prognostic factor and exhibits pro-oncogenic activity in pancreatic cancer. Oncogene. 2013;32:1616-25.

12. Li Z, Zhao X, Zhou Y, Liu Y, Zhou Q, Ye H, Wang Y, Zeng J, Song Y, Gao W, Zheng S, Zhuang B, Chen H, et al. The long non-coding RNA HOTTIP promotes progression and gemcitabine resistance by regulating HOXA13 in pancreatic cancer. J Transl Med. 2015;13:84.

13. Jiao F, Hu H, Yuan C, Wang L, Jiang W, Jin Z, Guo Z, Wang L. Elevated expression level of long noncoding RNA MALAT-1 facilitates cell growth, migration and invasion in pancreatic cancer. Oncol Rep. 2014; 32:2485-92.

14. Sun YW, Chen YF, Li J, Huo YM, Liu DJ, Hua R, Zhang JF, Liu W, Yang JY, Fu XL, Yan T, Hong J, Cao H. A novel long non-coding RNA ENST00000480739 suppresses tumour cell invasion by regulating OS-9 and HIF- $1 \alpha$ in pancreatic ductal adenocarcinoma. Br J Cancer. 2014;111:2131-41.

15. Peng $\mathrm{C}$, Li H, Shen B. Downregulation of gas 5 increases pancreatic cancer cell proliferation by regulating CDK6. Cell Tissue Res. 2013;354:891-6.

16. Peng W, Gao W, Feng J. Long noncoding RNA HULC is a novel biomarker of poor prognosis in patients with pancreatic cancer. Med Oncol. 2014;31:346.

17. Zheng S, Chen H, Wang Y, Gao W, Fu Z, Zhou Q, Jiang Y, Lin Q, Tan L, Ye H, Zhao X, Luo Y, Li G, et al. Long non-coding RNA LOC389641 promotes progression of pancreatic ductal adenocarcinoma and increases cell invasion by regulating E-cadherin in a TNFRSF10A-related manner. Cancer Lett. 2016;371:354-65.

18. Huang X, Zhi X, Gao Y, Ta N, Jiang H, Zheng J. LncRNAs in pancreatic cancer. Oncotarget. 2016;7:57379-90. https:// doi.org/10.18632/oncotarget.10545.

19. $\mathrm{Hu}$ P, Shangguan J, Zhang L. Downregulation of NUF2 inhibits tumor growth and induces apoptosis by regulating lncRNA AF339813. Int J Clin Exp Pathol. 2015;8:2638-48.

20. Kladi-Skandali A, Michaelidou K, Scorilas A, Mavridis K. Long noncoding RNAs in digestive system malignancies: A novel class of cancer biomarkers and therapeutic targets? Gastroenterol Res Pract. 2015; 2015:319861.

21. Burris HA 3rd, Moore MJ, Andersen J, Green MR, Rothenberg ML, Modiano MR, Cripps MC, Portenoy RK, Storniolo AM, Tarassoff P, Nelson R, Dorr FA, Stephens CD, Von Hoff DD. Improvements in survival and clinical benefit with gemcitabine as first-line therapy for patients with advanced pancreas cancer: a randomized trial. J Clin Oncol. 1997;15:2403-13.

22. De La Cruz MS, Young AP, Ruffin MT. Diagnosis and management of pancreatic cancer. Am Fam Physician. 2014;89:626-32.

23. Ren YQ, Zhang HY, Su T, Wang XH, Zhang L. Clinical significance of serum survivin in patients with pancreatic ductal adenocarcinoma. Eur Rev Med Pharmacol Sci. 2014;18:3063-8.

24. Prensner JR, Iyer MK, Balbin OA, Dhanasekaran SM, Cao Q, Brenner JC, Laxman B, Asangani IA, Grasso CS, Kominsky HD, Cao X, Jing X, Wang X, et al. Transcriptome sequencing across a prostate cancer cohort identifies PCAT-1, an unannotated lincRNA implicated in disease progression. Nat Biotechnol. 2011;29:742-9.

25. Gupta RA, Shah N, Wang KC, Kim J, Horlings HM, Wong DJ, Tsai MC, Hung T, Argani P, Rinn JL, Wang Y, Brzoska P, Kong B. Long non-coding RNA HOTAIR reprograms chromatin state to promote cancer metastasis. Nature. 2010;464:1071-6.

26. Quagliata L, Matter MS, Piscuoglio S, Arabi L, Ruiz C, Procino A, Kovac M, Moretti F, Makowska Z, Boldanova T, Andersen JB, Hämmerle M, Tornillo L. Long noncoding RNA HOTTIP/HOXA13 expression is associated with disease progression and predicts outcome in hepatocellular carcinoma patients. Hepatology. 2014;59:911-23.

27. Cheng Y, Jutooru I, Chadalapaka G, Corton JC, Safe S. The long non-coding RNA HOTTIP enhances pancreatic cancer cell proliferation, survival and migration. Oncotarget. 2015;6:10840-52. https://doi.org/10.18632/ oncotarget. 3450 .

28. You L, Chang D, Du HZ, Zhao YP. Genome-wide screen identifies PVT1 as a regulator of Gemcitabine sensitivity in human pancreatic cancer cells. Biochem Biophys Res Commun. 2011;407:1-6. 
29. Zhang S, Zhang G, Liu J. Long noncoding RNA PVT1 promotes cervical cancer progression through epigenetically silencing miR-200b. APMIS. 2016;124:649-58.

30. Wang F, Yuan JH, Wang SB, Yang F, Yuan SX, Ye C, Yang N, Zhou WP, Li WL, Li W, Sun SH. Oncofetal long noncoding RNA PVT1 promotes proliferation and stem cell-like property of hepatocellular carcinoma cells by stabilizing NOP2. Hepatology. 2014;60:1278-90.

31. Pang EJ, Yang R, Fu XB, Liu YF. Overexpression of long noncoding RNA MALAT1 is correlated with clinical progression and unfavorable prognosis in pancreatic cancer. Tumour Biol. 2015;36:2403-7.

32. Wu Y, Wang YQ, Weng WW, Zhang QY, Yang XQ, Gan HL, Yang YS, Zhang PP, Sun MH, Xu MD, Wang CF. A serum-circulating long noncoding RNA signature can discriminate between patients with clear cell renal cell carcinoma and healthy controls. Oncogenesis. 2016;5:e192.

33. De Vita F, Ventriglia J, Febbraro A, Laterza MM, Fabozzi A, Savastano B, Petrillo A, Diana A, Giordano G, Troiani T, Conzo G, Galizia G, Ciardiello F, Orditura M. NABpaclitaxel and gemcitabine in metastatic pancreatic ductal adenocarcinoma (PDAC): from clinical trials to clinical practice. BMC Cancer. 2016;16:709.

34. Leone F, Gatti M, Massucco P, Colombi F, Sperti E, Campanella D, Regge D, Gabriele P, Capussotti L, Aglietta M. Induction gemcitabine and oxaliplatin therapy followed by a twice-weekly infusion of gemcitabine and concurrent external-beam radiation for neoadjuvant treatment of locally advanced pancreatic cancer: a single institutional experience. Cancer. 2013;119:277-84. 